\title{
Una isla en un pequeño muñeco negro. El recorrido del significante Gorogó en Primera memoria de Ana María Matute
}

\section{An island in a small black doll. The path of the signifier Gorogó in Ana María Matute's Primera memoria}

\author{
Emilio Ceruti \\ LS Middlebury College \\ emilio.ceruti@gmail.com \\ ORCID iD: https://orcid.org/0000-0003-0836-7168
}

\section{RESUMEN}

Cuando proyectamos sobre un objeto una carga emotiva, este se convierte en una cosa que remite a nosotros mismos y, por ello, permite al sujeto conocerse mejor. En este estudio se analiza la relación entre un muñeco negro llamado Gorogó y los personajes de la novela Primera Memoria de Ana María Matute, para resaltar los significados que adquiere el significante Gorogó en sus desplazamientos a lo largo de la novela. Siguiendo los postulados de Lacan, es posible reconocer tres posiciones del muñeco. Cuando se queda escondido, proporciona cierto amparo a la protagonista. Cuando se revela y entra en relación con los demás personajes, desencadena lo siniestro (unheimlich) al ser una cosa que debía mantenerse escondida y que ha sido revelada. Al final, Gorogó destaca por su ausencia y revela la dimensión temporal de las cosas, esto es, el crecimiento de la protagonista y el conflicto interior que esto conlleva.

Palabras Clave: semiótica literaria; generación de 1950; primacía del significante; guerra civil española.

\begin{abstract}
When we project an emotional charge onto an object, this turns into a thing that refers to ourselves, and allows the subject to know himself/herself better. In this study, the relationship between a black doll called Gorogó and the characters of Ana María Matute's Primera Memoria will be analyzed in order to glimpse the signified that the signifier Gorogó acquires through its displacements. Following Lacan's postulates, it is possible to determine three positions of the doll. When it remains hidden, it confers a certain protection to the protagonist. When it is revealed and enters in a relationship with the other characters, it causes an odd sensation (unheimlich), for being a thing that had to be kept unseen and that has been revealed. At the end, Gorogó stands out for his absence and reveals the temporal dimension of things, namely, the protagonist's growth and the internal conflict that this entails.
\end{abstract}

Key words: Literary Semiotics; Generation of 1950; Signifier's Supremacy; Spanish Civil War. 


\section{INTRODUCCIÓN}

Tras la conclusión de la Segunda Guerra Mundial, la España franquista experimentó una década de aislamiento por parte de los vecinos países europeos, debido principalmente a las ayudas que Hitler y, sobre todo, Mussolini le proporcionaron al régimen dictatorial de Franco. Sin embargo, algunos acontecimientos, como el comienzo de la Guerra Fría, que vio dos principales potencias mundiales en conflicto (URSS y EE. UU.) y el triunfo de las democracias populares del oriente europeo, entre otros, empujaron a la ruptura paulatina del cerco hacia el régimen franquista. Así es que, en 1953, España firmó el Pacto de Madrid con EE. UU., que preveía ayuda económica y militar por parte de estos últimos a cambio de la cesión de algunas bases militares estadounidenses en la península ibéricaํ. De paso, España entró en la ONU en 1955 y en la OECE y el FMI en 1958.

Estas aperturas al exterior posibilitaron el comienzo de una modernización y un desarrollo económico industrial (se dio la tendencia a dejar el campo para mudarse a la ciudad) que modificaron las necesidades y aspiraciones del pueblo español, el cual manifestaba de manera creciente sus voluntades de libertad de expresión y consumo a través de protestas estudiantiles y obreras (Pittarello 2001).

En este contexto social y económico surgió el movimiento literario de los niños de la guerra o generación del medio siglo, esto es, una generación de escritores $^{2}$ que vivió la guerra española en los años de la infancia y cuyo estilo literario remite al realismo social, es decir, el tratamiento de los problemas sociales vigentes a través de un estilo sobrio que sin embargo tiene entregas de lirismo y subjetividad.

Este es el marco en el que se publicó Primera memoria de Ana María Matute (que ganó el Premio Nadal en 1959). La novela narra en primera persona las experiencias de una niña llamada Matia (voz narrante) que, a los catorce años de edad y tras la pérdida de su madre y la ausencia de su padre por haberse adherido supuestamente al frente republicano — guiado, según afirma la suegra del mismo, por «ideas infernales, hechos nefastos» (Matute 1960: 16) _ , se ve obligada a mudarse a la isla donde vive su abuela materna, mujer estricta, controladora y conservadora. La guerra española acaba de estallar y su presencia como telón de fondo se hace sentir, más que por ser mencionada apenas, por la ausencia de sus indicios patentes en la pequeña isla. Supuestamente se trata de la isla de Mallorca y no en balde la autora comete una falta

\footnotetext{
${ }^{1}$ Cabe recordar que la postura anticomunista de Franco favoreció el acercamiento del gobierno estadounidense, pues este último veía en él un potencial aliado en contra de la URSS.

${ }^{2}$ Entre los cuales cabe mencionar a Ignacio Aldecoa, Rafael Sánchez Ferlosio, Juan Goytisolo, Jesús Fernández Santos, Carmen Martín Gaite y Ana María Matute.
} 
de concreción sobre el lugar, en cuanto, por un lado y como se decía, no hay escenarios de guerra, pero, por otro, la guerra está muy presente en el ambiente represivo de la isla y de sus habitantes. De esta forma, Mallorca se convierte en cualquier lugar de España que esté bastante lejano de la guerra, pero lo suficientemente cercano para quedar afectado por las dinámicas sociales y políticas que se dan en la península. Aquí Matia vivirá el paso de la niñez a la edad adulta rodeada de una serie de personajes que la iniciarán a «las feas cosas de los hombres y de las mujeres» (Matute 1960: 127), esto es, el mundo de los adultos, que resulta, a los ojos de la protagonista, como un universo contaminado, cruel, viciado y mediocre. La sensación que tiene el lector es que el único aliado que tiene Matia es un muñeco, regalo de su padre, que le permite a la protagonista huir metafóricamente del desasosiego y las angustias que le produce el microcosmo social de la isla donde se ve atrapada. Ese muñeco pasa casi desapercibido, como algo inofensivo - espejo de una niñez que pronto debe acabar-, a los ojos de los personajes de la novela y se contrapone, en cierta medida, al personaje de Manuel, única figura positiva para Matia, el cual, sin embargo, será aniquilado y alejado tras un engaño del malvado Borja, primo y coetáneo de ella. Matia también contribuye a la derrota de Manuel, pues ella misma calla la verdad acerca de las mentiras de Borja: es esta una clave para entender la tristeza de la protagonista adulta, anunciada desde las primeras páginas de la novela.

De los personajes que pueblan esta novela hablaremos más adelante, ya que el objeto de este estudio es un muñeco negro llamado Gorogó. Mejor dicho, trataremos de dar luz a la relación entre esta cosa y los demás personajes, para tratar de vislumbrar los significados que adquiere el significante Gorogó en sus desplazamientos a lo largo de la novela. Por esta razón, seguiremos los postulados de Lacan para considerar la supremacía del significante sobre el significado, sin dejar de lado algunas consideraciones sobre el papel que las cosas adquieren en la vida de los sujetos, nuestras vidas.

\section{Ana María Matute y la Generación de MEdio SIGlo}

En la inmediata Postguerra, el panorama cultural español no gozaba de una producción literaria boyante. Destacan obras, como Nada (1944) de Carmen Laforet (Premio Nadal en 1945) y La familia de Pascual Duarte (1942) de Camilo José Cela. La censura obstaculizaba la difusión de una literatura social que criticara la fe y las buenas conductas promovidas por el catolicismo, de manera que muchos escritores de la época, como dice Goytisolo (1977), recurrieron a la alusión como estrategia para evitarla (no fue el caso de La Colmena de Cela, como veremos en breve).

En general, España estaba experimentando un aislamiento no solo político, sino también cultural y, como apunta Ferreras (1988), esto significó un paso 
atrás hacia el realismo decimonónico para volver a empezar. El sentimiento que prevalecía era una angustia existencial que se reflejaba en temáticas inherentes la soledad, la frustración, la inadaptación y la muerte. Se trataba de un realismo que fue abarcando una serie de inquietudes sociales que afloraron tras la publicación, en 1955, de La Colmena del ya mencionado Cela, que hasta entonces había visto su obra censurada por las alusiones al sexo en ella contenidas. Se abrió paso, de esta forma, al realismo social en la novela española, en cuanto, en algunas partes de La Colmena, el autor interviene comentando las actitudes de los personajes y adopta un estilo caracterizado por un lirismo que se nota, por ejemplo, en el poema del gitanillo (Cela 2010: 78) o en la secuencia en la que Leoncio Maestre piensa en doña Elvirita (Cela 2010: 174).

Asimismo, los novelistas que pertenecen a la generación de medio siglo, por lo general, adoptan un estilo sólido, aunque no faltan momentos de lirismo álgido, como se puede notar en el siguiente fragmento de Ignacio Aldecoa (1995: 244):

Estoy lejos en mi propio naufragio, siendo una presencia ajena, alguien que no puede compartir lo que sucede, alguien que no deja compartir lo que pasa. Todos mis riesgos están fuera de esta isla, y aquí en este regazo es donde se desencadenan otros riesgos que no me alcanzan.

Estos escritores son también definidos como niños de la guerra, pues vivieron la experiencia de la guerra civil en su niñez, y escriben en los años cincuenta empujados por la voluntad de transformar la sociedad española, denunciando las miserias e injusticias del acontecimiento bélico y sus secuelas. Así es que el realismo adquiere diferentes matices que ensalzan la comprensión de la realidad social y política de la cual deriva el clima de opresión y desamparo que viven los mismos autores. Ello lleva a la tendencia al autobiografismo que, junto a un fuerte lirismo, caracteriza la obra de Ana María Matute. No en balde, una de las temáticas más abordadas por esta autora es la de la infancia vulnerada (Bórquez 2011) y se nota desde su primera obra, Los Abel (1948), en la se da una imagen negativa de los niños, que hablan un lenguaje raro y juegan juegos oscuros, con piedras y barro, como efecto del entorno moral y social que se presenta como duro, triste y estéril. El compromiso social en las obras de Ana María Matute no es explícito, sino que se conforma a través del mundo lírico y sensorial de la imaginación de la autora, y se mezcla con la mirada realista que caracteriza la literatura de la época.

\section{El RECORRIDO DEL SIGNIFICANTE: LA COSA GOROGÓ}

Una de las mayores preocupaciones del psicoanalista Jacques Lacan es la de deslindar la relación entre el significado y el significante. De hecho, en uno 
de sus trabajos más conocidos, su Seminario sobre la carta robada (1955), lleva a cabo una reflexión sobre el papel que desempeña el significante carta en el cuento de Edgar Allan Poe de 1845: la escena se abre con un personaje ilustre sentado al tocador (que se descubrirá que es la reina) y que recibe una carta que pondría en peligro el honor y la seguridad de este personaje. La reina no está sola: con ella se encuentra el rey, el cual no se tiene que enterar de la existencia de la carta. De repente entra el ministro, hombre sin escrúpulos y de inteligencia criminal sin pares. Nota la carta, nota el aire preocupado de la reina cuando ella lo ve mirando la carta y entiende el gran poder que conlleva el uso potencial de la carta. A estas alturas, el ministro se apodera de la carta de la reina sustituyéndola con otra carta igual bajo la mirada de la reina, la cual no puede protestar por la legítima posesión de la carta, porque el rey no se tiene que enterar de su existencia. A la reina no le queda más remedio que agarrar distraídamente la carta dejada por el ministro y destruirla.

En el análisis de este cuento, Lacan observa que a través de los desplazamientos de la carta, verdadera protagonista del cuento, es posible determinar una serie de estados diferentes de la relación que los personajes entretienen con los movimientos de la carta. Lo interesante aquí es cómo los sujetos se relevan en sus desplazamientos, determinados por el lugar que ocupa la carta (que es puro significante). Los significados, para Lacan, son variaciones individuales cuyo dispositivo es determinado por el orden del significante. La carta es el significante de una ausencia y sus movimientos determinan el orden simbólico, los sujetos mismos. El objeto adquiere valor dentro de las interacciones de los personajes: antes de que entre el rey, es un objeto neutral en las manos de la reina; cuando cae en las manos del ministro se carga de otros significados, que son su uso potencial (y no su uso efectivo). De hecho, el uso de la carta disipa el poder del ministro, pero a la vez lo somete al objeto mismo. La atención, entonces, se centra en el no-uso de la carta: el poder del ministro es efectivo justamente porque la reina está consciente del uso potencial que el hurtador podría hacer de la carta.

El propósito de Lacan, como él mismo declara en el texto, es demostrar que las incidencias imaginarias entregan solo lo inconsciente de nuestra experiencia, a menos que se los refiera a la cadena simbólica que los conecta y los orienta. Sigue los postulados de Freud: el orden simbólico es constituyente para el sujeto y el recorrido de un significante es la determinación principal. Esto es lo que hace posible la ficción para nosotros: el hecho de que tengamos una necesidad simbólica.

El texto de Poe, traducido por Baudelaire como La lettre volée (The purloined letter), le permite a Lacan dibujar un modelo de intersubjetividad que deja vislumbrar el automatismo de repetición (que para Umberto Eco serán los automatismos del significante). El significante se mantiene en su desplazamiento, pues su funcionamiento exige que abandonemos un lugar para regresar circularmente. Esto es, la búsqueda constante de un encuentro con lo real. 
Para Freud, «el sujeto sigue el desfiladero de lo simbólico, pero [...] no es sólo el sujeto sino los sujetos, tomados en su intersubjetividad, los que toman la fila [...] moldean su ser mismo sobre el momento que los recorre en la cadena significante» (Lacan 1955: 40). En una palabra, citando a Freud, Lacan sostiene que el desplazamiento del significante determina a los sujetos, sus actos, su destino, etc.

Según Bodei (2009), lo que se contrapone etimológicamente al sujeto es el objeto (lat. objectum, obstáculo), pues en su origen implica una batalla que el sujeto gana sobre el objeto a través de la mera posesión, lo cual convierte la entidad poseída en algo insignificante, algo de uso meramente instrumental. Sin embargo, los objetos dejan de ser objetos y se convierten en cosas cuando proyectamos sobre ellos cierta dosis de inversión afectiva y, en cierta medida, nos permiten que nos comprendamos mejor a nosotros mismos. Escribe Bodei (2009: 115): "Le cose ci spingono a dare ascolto alla realtà, a farla 'entrare' in noi aprendo le finestre della psiche [...] le cose parlano tanto più di noi, di ciò che ci costituisce, quanto più le lasciamo esprimere nel loro linguaggio». También Italo Calvino (1995), en el brillante diálogo entre Praz y Cecchi, les otorga un rol central a las cosas, puesto que la presencia sensible de las cosas tiene una gran importancia, ya que el objeto es expresión del arte y huella del hombre en las cosas. Además, cabe volver a Freud, quien explica, a través de las palabras de Jentsch, que cuando en el lector (o espectador o interlocutor) se infunde una sensación de incertidumbre frente a la naturaleza de una cosa (si de verdad es un objeto inanimado o si, al contrario, es una entidad animada), se despierta en él el sentimiento de lo siniestro, sentimiento que puede remitir, por un lado, a una dimensión no familiar, de desamparo frente a lo desconocido, o bien, por otro, puede reconducir a la acepción de algo revelado y que, sin embargo, tenía que mantenerse escondido, secreto (Freud 1991) ${ }^{3}$.

Como dijimos en la introducción, es justamente a partir del análisis de los desplazamientos de una cosa cómo analizaremos la novela de Ana María Matute (1960). Es más, el análisis se centrará en la relación entre las posiciones (o simulacros, en la acepción de Greimas y Fontanille, 2009) del muñeco negro Gorogó (la cosa) y los personajes que actúan en la novela. Como veremos durante el análisis, Gorogó desencadena efectos de sosiego en el ánimo de la joven protagonista, pero son sentimientos que se convierten en su opuesto

${ }^{3}$ Freud (1991) explora la dimensión de lo perturbador a partir de la etimología de la palabra y explica que el término alemán heimlich tiene dos acepciones: la primera es casa, familiar; la segunda es secreto, escondido. Entonces, su contrario, unheimlich, apunta a algo inconsueto y desconocido, por un lado, e indica algo que aflora aunque hubiera debido mantenerse secreto. También Barthes (2003: 41) menciona el heimlich como sentimiento de amparo al mirar una fotografía que despierta un deseo fantasmático, el cual aflora de «una sorta di veggenza che sembra portarmi avanti, verso un tempo utopico, o riportarmi indietro, non so verso quale regione di me stesso». 
cuando el muñeco se manifiesta y entra en contacto con los adultos. Veremos, por ende, a Gorogó escondido (heimlich, el amparo, lo familiar y conocido), a Gorogó revelado (unheimlich, una cosa que debía mantenerse escondida) y, finalmente, al Gorogó ausente, la privación que supone una congoja necesaria en el proceso de crecimiento de Matia.

\section{El MUÑECO ESCONDIDO: LA ISLA PERSONAL DE Matia}

La novela de Matute se abre en el espacio de la isla, donde Matia, la protagonista de catorce años, vive con su abuela doña Práxedes, su tía Emilia y el primo Borja. De inmediato el lector percibe, a través de las palabras de Matia, el estado de angustia que le proporciona la vivencia en ese núcleo familiar. Además, Matia acaba de ser expulsada del colegio Nuestra Señora de los Ángeles, lo cual incrementa la irritación de su abuela, mujer muy conservadora, derechista y católica. El comportamiento de la abuela se enmarca en un fuerte matriarcado que se ha generado frente a la inexistencia del hombre: este último participa luchando en la guerra civil (como voluntario o no) y las mujeres ocupan los espacios que hasta entonces habían sido destinados a los hombres. De hecho, Güerri Martín ${ }^{4}$ escribe:

La guerra civil había trastocado la vida cotidiana de las mujeres y modificando los estilos de vida habituales. Al calor de las dificultades bélicas, habían adquirido una mayor autonomía de movimiento y de decisión de las que hicieron uso, y descubrieron un interés por la política que hasta entonces no habían tenido, ocupando espacios públicos sin abandonar sus esferas privadas.

Doña Práxedes, entonces, mantiene una actitud autoritaria para estar al mando de su microcosmo y, siendo de ideología falangista, se apoya en el modelo femenino promovido por la Falange, esto es, una mujer que tenía que «crear familias con una base exacta de austeridad y alegría, educadas en la doctrina cristiana y en los principios del nacionalcatolicismo que serían más tarde útiles en la Familia, en el Municipio y en el Sindicato» ${ }^{5}$. En las palabras de Concha Espina (cit. en Langa Nuño 2007: 27), se trata de un «matriarcado mariano», ultracatólico, que en cierta medida representa «una reivindicación de lo femenino ante lo masculino».

Cuando Matia deja la casa donde vivía con Mauricia, el aya, pierde el teatrito y todo lo relacionado con su vida antes de la estadía forzosa con la

${ }^{4}$ Véase: Güerri Martín, Carmen (s. f.). «La mujer durante la guerra civil», en Carmen Güerri Martín, La guerra civil española, pp. 298-378. Material didáctico accesible en: http:// www.laguerracivilenelaula.paramnesia.es/LAGUERRACIVILENELAULA/LA_GUERRA_ CIVIL files/mujerguerracivil.pdf [Última consulta: 11/12/2016].

5 İdem: 373. 
odiada abuela en una isla que despierta en ella sentimientos de desasosiego. Lo único que le queda de ese pasado es Gorogó: «Menos mal que llevé conmigo, escondido entre el jersey y el pecho, mi Pequeño Negro de trapo - Gorogó, Deshollinador - y lo tenía allí, debajo de la almohada» (Matute 1960: 18).

En el fragmento que acabamos de presentar, se introduce por primera vez al muñeco Gorogó, escondido debajo del jersey o de la almohada. Y en efecto, a lo largo de la novela, Matia tratará de esconder a Gorogó, para que pase desapercibido a los ojos de los demás, adultos y adolescentes que actúan con la crueldad de los adultos. En particular, nos referimos al personaje de Borja, descrito por la narradora como «pillo, embustero, traidor [...] impío, débil y soberbio pedazo de hombre» (Matute 1960: 15).

De hecho, Matia rehúsa el mundo de los adultos; en más de una ocasión declara no querer saber «las feas cosas de los hombres y de las mujeres», pues sabe muy bien que no quiere ser como ellos. La imagen que la protagonista tiene de la realidad que la rodea no es nada alentadora, al contrario se siente oprimida por la mezquindad que, día tras día, ve en ella. Conque al ocultar a Gorogó a la vista de los demás es como si preservara su integridad, como si huyera de la contaminación de lo que está a su alrededor. Sin embargo, cabe destacar que Matia siente atracción hacia un adulto misterioso, Jorge de Son Major, quien, ya mayor, tras conducir una vida irresponsable y maravillosa navegando entre las islas griegas, ahoga en el alcohol su nostalgia hacia el pasado:

Verle allí, con su raída chaqueta de marino, en el jardín amurallado, Jorge de Son Major, refugiado en oscuras rosas, en recuerdos. Deseaba alcanzar, beber sus recuerdos, tragarme su tristeza ("gracias, gracias por tu tristeza"), refugiarme en ella para huir, como él, hundido para siempre en la gran copa de vino rosado de su nostalgia, que me invadía mágicamente (Matute 1960: 166).

También Matia tiene sentimientos positivos hacia Manuel, un adolescente estigmatizado por los coetáneos — sobre todo por Borja, quien le define como un «pelirrojo como todos ellos [...]. Pelirrojo. Chueta asqueroso» (Matute 1960: 23) - por ser el hijo natural del concubinato entre su madre y Jorge de Son Major, e hijo adoptado del republicano José Taronjí, asesinado por los falangistas. Manuel, del cual también se hablará más adelante, sucumbirá tras una mentira bien armada por Borja y terminará en un reformatorio.

En estas dinámicas, Matia siente frustración con respecto a la sociedad que la rodea: «no entiendo nada de lo que ocurre en la vida ni en el mundo, ni alrededor de mí: desde los pájaros a la tierra, desde el cielo al agua, no entiendo nada» (Matute 1960: 139). La protagonista sufre al no poder hacer lo que hacen los adolescentes niños: tiene que aprender a bordar, a hablar francés y a comportarse según el protocolo social. Intenta llevar a cabo unas pequeñas rebeldías, como fumar a escondidas o lleva el pelo suelto. Sin embargo, tiene 
que ceder a los chantajes de su primo Borja, cuando el mismo amenaza contarle a la abuela una supuesta relación sexual entre Matia y Manuel si ella no calla la verdad sobre el acontecimiento que ha condenado a Manuel, porque sabe que la abuela le creería a Borja y que una de las peores insinuaciones hacia una adolescente concierne a un comportamiento sexual indecente. En este contexto, la mujer no puede tener sentimientos y la misma abuela le dice a Matia que la belleza «es lo único que sirve a una mujer, si no tiene dinero» (Matute 1960: 96). Es más, en un fragmento, Matia imagina a Manuel diciéndole: «Vuelve, vuelve, que te casarán con un hombre blando y seboso, podrido de dinero, o con un látigo bestial, como el tío Álvaro» (Matute 1960: 115).

Gorogó, entonces, es el refugio simbólico para Matia. Es también la cosa en la cual la narradora encarna su esencia de niña, que no puede hacer las cosas que hacen los niños, y su estado de pureza todavía no contaminado por la corrupción de los adultos.

Contra todos ellos, y sus duras o indiferentes palabras; contra el mismo Borja y Guiem, y Juan Antonio; contra la ausencia de mis padres, tenía yo mi isla: aquel rincón de mi armario donde vivía, bajo los pañuelos, los calcetines y el Atlas, mi pequeño muñeco negro. Entre blancos pañuelos y praderas verdes y mares de papel azul, con ciudades como cabezas de alfiler, vivía escondido a la brutal curiosidad ajena mi pequeño Gorogó (Matute 1960: 100).

Puede parecer que Gorogó tenga una posición rara (odd, bizarre) al estar escondido dentro de un armario o debajo de la almohada o un jersey, tal como la tiene la carta del cuento de Poe cuando está en manos del ministro, quien, en lugar de esconder la carta, la ostenta, convencido de que nadie pensará que ha escogido un lugar manifiesto para mantener escondida la carta. Así es para Matia: los niños suelen enseñar sus muñecos, los llevan consigo adonde fuera que vayan, cogiéndolos de un brazo o una pata o una pierna, arrastrándolos hasta cualquier lugar que decidan pisar; sin embargo, Matia escoge un lugar raro para su muñeco, esto es, un lugar secreto, donde solo esté para ella. De esta manera, Gorogó desencadena un sentimiento familiar (heimlich) cuando se queda escondido y, sin embargo, la necesidad misma de mantenerlo oculto aviva en Matia el desamparo (unheimlich) con relación al mundo que la rodea.

Gorogó, entonces, existe solamente para ella, no para con los demás que ya están perdidos. No hay salvación para los adultos y los que actúan de adultos, y por ende no es conveniente que estos entren en contacto con él, arriesgando comprometerlo y destruir sus efectos protectores sobre la inocencia de Matia. 
El MUÑECo REVELAdo: El MUNDO DE AFUERA (O LA ISLA DE LOS ADUlToS)

La guerra está presente en su ausencia, tal como Gorogó. La guerra aflora a través de lo relatado, los artículos de periódico que la abuela de vez en cuando lee y menciona. Nunca se configura como información de primera mano. Asimismo, cuando los otros incurren en ese muñeco, este adquiere otro significado, esto es, un desvío de la realidad, pues se supone que Matia relegará al pasado su niñez y comenzará a encararse al mundo de los adultos, que es un mundo poblado de guerras, hastío, injusticias, privaciones. El rechazo de Matia hacia este mundo causa el hecho de que se la critique y se la aparte. Borja tiene más o menos la misma edad de Matia, sin embargo actúa como un adulto; de hecho, su forma de actuar delata la hipocresía y el materialismo que caracterizan a la mayoría de los personajes de la novela y, en más ocasiones, sus rasgos físicos y sus ademanes recuerdan a los de la abuela, quien representa el prototipo de la crueldad: «Noté que [Borja] miraba por encima de su libro abierto. Las pupilas verde pálido parecían de cristal hueco. ("La mirada de la abuela"). Le hice una mueca» (Matute 1960: 201); «Borja hizo un gesto extraño con las manos que me recordó a la abuela» (Matute 1960: 195).

El personaje que se opone simbólicamente a Borja es el ya mencionado Manuel Taronjí, un muchacho de catorce años por el cual la protagonista siente una fuerte empatía. A través de este personaje, Matia descubre las injusticias sociales: como se decía, Manuel es discriminado y apartado por el resto de la sociedad no solo por el concubinato de su madre con Jorge de Son Mayor, sino también porque es hijastro de José Taronjí, tachado de rojo y, por consiguiente, asesinado por los falangistas. Al descubrir el secreto de Manuel, «un secreto sucio de hombres y mujeres» (Matute 1960: 126), Matia se da cuenta de que no se puede evitar el proceso de crecimiento e ingreso en ese mundo que ella tanto rechaza:

Él está con los hombres: con las feas cosas de los hombres y de las mujeres. Y yo estaba a punto de crecer y de convertirme en una mujer. O lo era ya, acaso. Sentí las manos frías, en medio del calor [...]. Era yo, yo misma, y nadie más, la que traicionaba a Gorogó y a la isla del Nunca Jamás. Pensé: «¿Qué clase de monstruo soy ahora $[\ldots]$ que ya no tengo mi niñez y no soy, de ninguna manera, una mujer?» (Matute 1960: 127-128).

Callando el engaño de su primo a Manuel, Matia es consciente de que está traicionando a la única persona a la cual ha dado y de la cual ha obtenido una forma de amor. En este sentido, la compañía de Manuel había abierto nuevos horizontes para Matia, iniciándola en el proceso de crecimiento hacia el mundo de los hombres y las mujeres. Podemos deducir los arrepentimientos de la narradora cuando la enunciación se atañe al tiempo de la escritura, que es el de una mujer adulta, consciente de sus faltas. 
Manuel, entonces, tiene la misma función de figura deshollinadora que cumple Gorogó. Sin embargo, este es un Gorogó revelado, cuyos secretos están al alcance de todos, y al ser cosa manifiesta atrae los sentimientos malvados que pertenecen al mundo de los adultos. La abuela, Borja y los demás habitantes de la isla desprecian y atacan a Manuel y a su madre como reflejo de las partes en conflicto en la recién estallada guerra civil: de hecho, los primeros son católicos y ultraderechistas, mientras que Manuel y su familia son judíos y republicanos. Destruyendo a Manuel, Borja rompe la esperanza de Matia de huir del orden social al que se debería conformar, y por eso ella misma trata de mantener a Gorogó escondido, a salvo de las miradas corruptas de aquellos que lo contaminarían y acabarían con él y todo lo que representa para la protagonista. He aquí la otra acepción de unheimlich, esto es, una cosa que debía mantenerse escondida y que ha sido revelada y, por eso, engendra el sentimiento de lo siniestro.

Matia no quiere revelar a Gorogó ni siquiera al que parece ser el más inocuo de los personajes que la rodean, esto es, la tía Emilia. Esta vive de recuerdos y esperas, en una bola de humo y alcohol, constantemente asomada a la ventana en espera de la llegada, que nunca se cumplirá, de su esposo. Realmente, a lo largo de la novela, se descubrirá que hasta la tía Emilia tiene secretos que tienen que ver con las cosas sucias de los hombres y de las mujeres, y que su enajenación y extrañamiento se deben a lo que Matia descubre acerca de las cartas amorosas que la tía Emilia le escribía a Jorge de Son Major.

Sea como fuere, Gorogó no se tiene que asomar al mundo de los adultos, pues terminaría aniquilado igual que Manuel. Cuando la tía Emilia descubre el muñeco escondido debajo de la ropa, lo agarra y:

En lugar de burlarse dijo:

— ¡Ah, es un muñeco!... Sí, yo también dormía con un muñeco, hasta casi la víspera de casarme.

Levanté la cabeza para mirarla, y vi que sonreía. Se lo quité de las manos y lo volví a poner bajo la almohada, pensando: «No es eso, ya no duermo abrazada a Gorogó [...]. Este es para otras cosas; para viajar y contarle injusticias. No es un muñeco para quererle, estúpida» (Matute 1960: 110).

La tía sujeta el significante Gogoró, que en sus manos la proyecta en su inocencia pasada. Sin embargo, en manos de la tía, el muñeco adquiere una dimensión afectiva distinta a la de la protagonista: si para Emilia esa cosa era el destinatario de un querer, para Matia es el testigo de las injusticias del mundo adulto. Por esta razón, Matia cae en la corrupción de los adultos y ya no puede abrazar a su muñeco. Y justamente al final de la novela, como veremos en breve, Gorogó desaparece, pues Matia sale de la isla para enfrentarse sola a su vida de adulta, tal como el muñeco de la tía deja de cumplir su función cuando ella se casa. No es que se vaya a perder el significado de las cosas, es 
que simplemente habrá otros objetos en los cuales proyectar estados de ánimo y cargas emotivas.

\section{EL MUÑECO AUSENTE Y LA TEMPORALIDAD DE LAS COSAS}

Los recuerdos que Gorogó despierta en la tía Emilia son la demostración de que las cosas que nos acompañan no solo amplían el conocimiento de nosotros mismos, sino que también

... remite[n] a la temporalidad de quien posee o desea o sencillamente nota lo que está a su alrededor [...]. Los objetos son cosas en el sentido originario de causas, su etimología latina: apariencias sensibles que remiten a la conducta de los sujetos que las manipulan, las guardan o las abandonan [...] y pasando de mano en mano, mezclan simbólicamente el tiempo perdido de los muertos con el tiempo disponible de los vivos (Pittarello 2005: 18-19) ${ }^{6}$.

Según Bodei (2009), de hecho, las cosas nos brindan varios tipos de información: el autor dice que un muñeco nos puede decir el tipo de materiales que se empleaban en una determinada época para construir juguetes, o bien nos puede informar sobre las prácticas sociales en juegos infantiles de cierto período, o hasta pueden evocar escenas familiares. La temporalidad de las cosas evoca, a través de las cosas mismas, situaciones, estados de ánimo o experiencias vividas por nosotros mismos o por otras personas. Es un juego intersubjetivo hasta cuando esta intersubjetividad se da en el mismo sujeto, desdoblado en un ser-anterior y un ser-vigente.

En efecto, volviendo al principio de la novela, precisamente cuando Matia habla por primera vez de Gorogó, al mirarlo afirma:

Entonces comprendí que había perdido algo: olvidé en las montañas, en la enorme y destartalada casa, mi teatrito de cartón [...]. Y sentí una rabia sorda contra mí misma. Y contra la abuela, porque nadie me recordó eso, y ya no lo tenía. Perdido, perdido, igual que los saltamontes verdes, que las manzanas de octubre, que el viento en la negra chimenea (Matute 1960: 18-19).

En Gorogó no se halla solo su presente, sino también su pasado y los demás objetos perdidos que pertenecían a esa dimensión pretérita. En la protagonista se crea, de esta forma, una tensión que oscila entre el pasado y el presente (y, por consiguiente, se proyecta hacia el porvenir también). Gorogó es el único testigo de lo que fue, y el extravío de las demás cosas que poblaban su vida antes de la llegada a la isla aumenta el apego que Matia tiene hacia el muñeco

${ }^{6}$ Pittarello escribe estas reflexiones acerca de las obras de Javier Marías. Sin embargo, por el valor trascendental de estos conceptos, sentimos que también aplican a nuestro caso. 
negro. Pittarello (2005: 24) escribe: «La identidad [...] es lábil y fragmentaria: un rompecabezas incompleto, con piezas sueltas muy precisas, donde las cosas son trámites que anulan simbólicamente distancias cronológicas y barreras físicas»».

El muñeco negro, entonces, no solo simboliza el espacio donde Matia encuentra sosiego, sino que también encarna el paso del tiempo. Hasta la ausencia de este significante tiene un significado, es decir, el abandono de la niñez para encaminarse hacia la adolescencia. Hay un preludio de este pasaje en un fragmento de la novela, en el cual Matia se da cuenta de que algo está cambiando en las prácticas lúdicas con el primo Borja. Precisamente, Matia se da cuenta de que está creciendo y la falta de Gorogó en la escena hace más patente este presagio:

Estaba ya acostada, sin Gorogó, con la mano derecha bajo la almohada, fría aún [...] Y oí: tac, tac, tac. «No, Borja, por favor», me dije. Hacía mucho tiempo que no íbamos a la logia, de escondite, a fumar cigarrillos y cuchichear. «Oh, no, Borja, ya se acabó todo eso» (Matute 1960: 148).

La ausencia de Gorogó es permanente y definitiva al final de la novela: cuando Matia deja la isla, busca a Gorogó, pero no lo puede encontrar.

Y de pronto estaba allí el amanecer, como una realidad terrible, abominable. Y yo con los ojos abiertos, como un castigo. (No existió la Isla del Nunca Jamás y la Joven Sirena no consiguió un alma inmortal, porque los hombres y las mujeres no aman, y se quedó con un par de inútiles piernas y se convirtió en espuma.) Eran horribles los cuentos. Además, había perdido a Gorogó — no sabía dónde estaba, bajo qué montón de pañuelos o calcetines. Ya estaba la maleta cerrada, con sus correas abrochadas, sin Gorogó (Matute 1960: 211).

La maleta cerrada, abrochada, envuelta en sus correas: ya no puede entrar nada, así que Gorogó se queda afuera. Así, para Matia, comienza un nuevo viaje, que poco a poco se llenará de cosas que, de una forma u otra, le recordarán quién es y quién fue. En este sentido, Matia no puede sustraerse al ingreso en la adolescencia para dar paso luego a la edad adulta, por más que ella lo rechace. Así que el muñeco negro, que es isla idealizada, se extravía dentro de la isla real, la parte más cruel del mundo de Matia, y allí se queda con todos los pesares, malestares y angustias. En una palabra, tal y como decíamos hace poco, el significante Gorogó tiene un significado también en su ausencia, esto es, el conjunto de actos no cumplidos que se relacionan con la pérdida de la inocencia tras la traición a Manuel. Es la privación angustiosa y congojosa que acompañará a Matia hacia la edad adulta.

Quizás, un día, alguien encuentre a Gorogó y lo reviva como cosa a su manera; asimismo, muy probablemente, Matia tendrá que proyectar una cantidad de energía afectiva en otro objeto que le permita seguir conociéndose 
mejor a sí misma, en unas etapas de su existir en que Gorogó ya no la puede ayudar, sino en la remembranza de otras cosas, que se le manifestarán en el camino de su vida, puedan evocar.

\section{A MODO DE CONCLUSIÓN}

En este trabajo, hemos observado los simulacros de la cosa-Gorogó. Sus desplazamientos sugieren diferentes posiciones de los sujetos, esto es, diferentes significados del mismo significante.

El muñeco permanece casi siempre en manos de la protagonista y las pocas veces que se revela a los demás también permite la epifanía de los estados de ánimo, las actitudes, los sentimientos y, en definitiva, la esencia de los personajes con quienes entra en relación.

A lo largo del análisis, hemos podido identificar tres tipos de modalidades en que Gorogó ocupa los espacios de la novela, a saber: escondido, revelado y ausente.

Cuando Gorogó se mantiene escondido a los ojos de los demás y se cela debajo de la ropa o la almohada, existe solo para la protagonista. En esta posición, puede preservarla de la corrupción del mundo que la rodea y le proporciona ese sentimiento del heimlich (el amparo). Sin embargo, la relación entre su posición escondida y los demás personajes saca a luz el sentimiento opuesto, el del unheimlich (lo siniestro), pues es la necesidad misma de no revelarlo la que provoca esa tensión en Matia.

Justamente cuando Gorogó se manifiesta, entonces se cumple el unheimlich, en la acepción de lo siniestro engendrado por la revelación misma de la cosa que debía permanecer escondida. La diferencia entre esta posición del significante y la anterior se halla en la proyección y realización de la revelación: en el primer caso, se trata de una proyección hacia el desamparo que significaría la manifestación de Gorogó y, más precisamente, hacia la ruptura de la sensación de familiaridad y sosiego que le confiere esa cosa a la protagonista mientras permanezca en una posición oculta; sin embargo, en el segundo caso, ya no es proyección de los sentimientos de Matia lo que provoca el unheimlich, sino la realización misma y lo que esta desencadena en los demás personajes.

Al final de la novela, Gorogó se convierte en una cosa ausente, que remite a una pérdida: la inocencia de la protagonista. Aun en su ausencia, Gorogó adquiere un significado y deja vislumbrar más que nunca la dimensión temporal de las cosas. Esta posición del significante es fundamental para el desarrollo psicológico de Matia, pues marca el paso no solo de la niñez a la edad adulta, sino también de la integridad moral a la culpa. Si Matia hubiese elegido a Manuel en lugar del primo, habría evitado este paso: al final prevalece la genealogía familiar representada por la abuela y Matia se asimila a los parien- 
tes que ella misma despreciaba. He aquí el conflicto personal que la novela deja implícito y tácito.

\section{BIBLIOGRAFÍA CITADA}

Aldecoa, Ignacio (1995). Parte de una historia. Madrid: Alfaguara.

Barthes, Roland (2003). La camera chiara. Nota sulla fotografia. Torino: Einaudi.

Bodei, Remo (2009). La vita delle cose. Bari: Laterza.

Bórquez, Néstor (2011). «Memoria, infancia y guerra civil: el mundo narrativo de Ana María Matute», Olivar. 12, 16, pp.159-177.

Calvino, Italo (1995). «La redenzione degli oggetti», en Mario Barenghi (ed.), Saggi 19451985. Torino: Einaudi, pp. 19-24.

Cela, Camilo José (2010). La Colmena. Madrid: Cátedra.

Ferreras Tascón, Juan Ignacio (1988). La novela en el siglo XX (desde 1933). Madrid: Taurus.

Freud, Sigmund (1991). «Il perturbante», en Sigmund Freud, Saggi sull'arte, la letteratura e il linguaggio. Torino: Bollati-Boringhieri, pp. 267-307.

Goytisolo, Juan (1977). «La novela española contemporánea», en Juan Goytisolo, Disidencias (pp.166-167). Barcelona: Seix Barral.

Greimas, Algirdas Julius y Fontanille, Jacques (2009). Semiótica de las pasiones. De los estados de cosas a los estados de ánimo. Méjico: Siglo XXI.

Lacan, Jacques-Marie Émile (1955). «Seminario sobre la carta robada», en Jacques-Marie Émile Lacan, Escritos (2001). Méjico: Siglo XXI, pp. 5-55.

Langa Nuño, Concha (2007). De cómo se improvisó el franquismo durante la guerra civil: La aoprtación del ABC de Sevilla. Sevilla: Centro de Estudios Andaluces.

Matute, Ana María (1960). Primera memoria. Barcelona: Destino.

Pittarello, Elide (2001). «Il romanzo», en Maria Grazia Profeti (ed.), L'eta contemporanea della letteratura spagnola. Firenze: La Nuova Italia, pp. 531-659.

Pittarello, Elide (2005). «Haciendo tiempo con las cosas», en Irene Andres-Suarez y Ana Casas (eds.), Javier Marias - Grand Seminaire de Neuchatel. Madrid: Universidad de Neuchatel y Arco/Libros, pp. 17-48.

Fecha de recepción: 16 de junio de 2015.

Fecha de aceptación: 18 de octubre de 2016. 